CHAPTER 3

\title{
Disciplinarity and Disparity in Applied Linguistics
}

Henry Widdowson, University of Vienna

I am greatly honoured to be invited to address you on this occasion, to represent the sadly dwindling number of BAAL veterans who were there at the founding of this association. And it is good to know that the traditional respect for the aged is itself not entirely a thing of the past. This respect does not, of course, necessarily extend to what opinions they express. 'Do not let me hear of the wisdom of old men,' and I do not claim that wisdom is what you are going to get. What you will get is my own view of applied linguistics as I see it from the perspective of the past. This is not the first time I have held forth about what applied linguistics is, or should be, all about and so this talk is in part a kind of collage, the variation on a theme whereby I take up, and take further, issues I have raised elsewhere (Widdowson 1980, 2000, 2005). So you may not hear anything in the way of wisdom in what I have to say, but I hope it just might stimulate some critical thinking about the activity that 50 years ago this association was founded to promote.

How applied linguistics is to be defined has always been a matter of contention, but there is general agreement that it has two distinguishing features. One is that its purpose is to engage with problems to do with language that are

How to cite this book chapter:

Widdowson, H. 2019. Disciplinarity and Disparity in Applied Linguistics. In: Wright, C., Harvey, L. and Simpson, J. (eds.) Voices and Practices in Applied Linguistics: Diversifying a Discipline, pp. 33-49. York: White Rose University Press. DOI: https:// doi.org/10.22599/BAAL1.c. Licence: CC BY-NC 4.0 
experienced in the real world. The other is that the means to achieving this purpose are essentially disciplinary in that they derive from specific academic fields of enquiry. Over recent years, it has been insisted that a defining feature of AL is not, as its name might misleadingly suggest, that it is only concerned with the discipline of linguistics but that other disciplines too must necessarily be involved in its engagement with problems in the real world. So the distinctive feature of AL, it is claimed, is its interdisciplinarity:

It is perhaps uncontroversial to claim that applied linguistics, in becoming more interdisciplinary, is better prepared for the principled handling of a range of distinct types of real world issues, and more critically aware of its methodologies.

(Bygate \& Kramsch 2000: 2)

The assumption here is that the more wide-ranging your disciplinarity, the better prepared you are to handle real-world issues.

When BAAL was first founded, these issues were predominantly to do with the pedagogy of second or foreign language teaching. Since then, of course, the range of issues thought to be amenable to applied linguistic handling has extended considerably. In the blurb on the cover of the Routledge Handbook of Applied Linguistics (Simpson 2011), Lantolf tells us that

... the field has come a long way since its early focus on the teaching and learning of languages beyond the first.

This seems to suggest that the early focus was a feature of the fledgling stage of applied linguistics, before it took wing into interdisciplinarity and so, by definition, extended its preparedness to handle a wider range of problems - this at the same time, of course, has the desirable consequence of enhancing its institutional status as an academic field of enquiry.

At the risk of seeming to be out of date, however, my focus will indeed be on how the discipline of linguistics has informed the applied linguistics of language teaching and how far this substantiates the belief, assumed to be self-evident, that there is a unilateral dependency relationship between disciplinarity and the handling of real-world issues. The field has indeed come a long way since its earlier years, and what I want to do is to go back and trace the path it has followed, the milestones and the landmarks along the way, the bifurcations, the roads taken - and not taken - in the developments in language teaching that have claimed an applied linguistic endorsement.

Back then to the past. Back beyond the momentous event of the founding of BAAL 50 years ago to 1957 and another event, even more momentous in its effect - the publication, as everybody knows, of a slim volume called Syntactic Structures by a then unknown young linguist, Noam Chomsky. What is perhaps not such common knowledge is that 1957 was also the year of publication of 
another work. This was a less slim volume entitled Papers in Linguistics and written by a much older and then well-known scholar, J.R. Firth. Although these two books appeared at the same time, that is just about the only thing they have in common for though both are concerned with defining the discipline of linguistics, they do so in radically different, indeed disparate, ways. And, as I shall argue, this disparity has been carried over into subsequent developments in applied linguistics.

Chomsky's definition of linguistics is, as he himself recognises, the traditional one proposed some 40 years earlier by de Saussure, namely the study of the formal properties of language abstracted from the actuality of their use, what he later called 'I-linguistics.' His book is devoted to the formulation of a clearly focused and coherent theoretical argument in its support. For Firth, on the other hand, linguistics is essentially all about developing a theory of how language is put to contextual use. It is the study of 'linguistic events in the social process,' to quote from his paper Personality and Language in Society (Firth 1957: 181), and as such is directly opposed to the 'structural formalism' of Saussure, which he says reduced language to 'a system of signs placed in categories' (Firth 1957: 180).

Firth's own formulation of such a theory in his 1957 publication is, in stark contrast with Chomsky, unsystematic and unclear. As Palmer remarks:

Given that the theory supposedly represented in Papers in Linguistics is so elusive of description, and apparently so susceptible to variable interpretation, even by those most closely acquainted with it, it is not to be wondered at that it succumbed to the invading force of a new theory, so explicitly propounded by Chomsky in Syntactic Structures.

(Palmer 1968: 8-9)

A notable success of this invading force, of particular significance for BAAL, was the capture in 1964 of the neo-Firthian stronghold of Edinburgh. In that year was founded a new chair in general linguistics. Michael Halliday, a pupil of Firth, had already been a lecturer and then reader in general linguistics for several years and had been developing his own extension of Firth's ideas in what was later to become his Systemic Functional Grammar. It seems to have been generally assumed that his appointment to the chair was a more or less foregone conclusion. Instead, the person appointed was John Lyons, a scholar whose linguistics was in accord with the 'new theory' and of the very 'structural formalist' kind that Firth, and Halliday, were opposed to. In his contribution to a volume of papers dedicated to the memory of Firth, who had died in 1960, Lyons makes the rather less than complimentary comment that

... there are those who would deny that Firth ever developed anything systematic enough to be described as a theory.

(Lyons 1966: 607) 
So one can say that this professorial appointment gave institutional recognition of a doctrinal disciplinary shift from context focused linguistics, the study of language in use, to code focused linguistics, the study of formal linguistic properties. In this respect, 1964 was, like 1957, another milestone date in the annals of the discipline of linguistics.

But 1964 was also a notable date in the annals of applied linguistics. For in this year not only was Pit Corder, the first chair of BAAL, appointed head of the newly named Department of Applied Linguistics in Edinburgh, but it was also the year of publication of Halliday, McIntosh and Strevens's The Linguistic Sciences and Language Teaching, the culmination of the activities that Halliday and his colleagues had carried out over the preceding five years in the previously named School of Applied Linguistics, itself founded in 1957. The description of 'the linguistic sciences' in this 1964 book, however, showed no sign of any invasive influence of the 'new theory' initiated by Syntactic Structures. There is no mention of it in the index.

The Linguistic Sciences and Language Teaching was a highly influential book and was taken at the time as being a kind of applied linguistic manifesto. Its very title explicitly relates the two supposedly distinctive features of applied linguistics and indicates the direction of their dependency. Its title is The Linguistic Sciences and Language Teaching and not Language Teaching and the Linguistic Sciences. This is how the relationship is described:

He (the language teacher) $[$ sic] is not teaching linguistics. But he is teaching something which is the object of study of linguistics, and is described by linguistic methods. It is obviously desirable that the underlying description should be as good as possible, and this means that it should be based on sound linguistic principles.

(Halliday et al. 1964: 66)

The obvious question that arises here is how to determine which linguistic principles are sound and when a description is good? As we have seen, Chomsky and Firth have diametrically opposing ideas about what 'the object of study of linguistics' should be. For one it is the formal features of the linguistic code, for the other how language is put to contextual use. Although both may go under the same name, what we have here are two different objects of study with different linguistic principles and methods - in short, two disparate disciplines. So which one should language teaching be based on? The answer obviously depends on your disciplinary allegiance. And so it came about that applied linguistics also developed in two disparate ways over the years.

These two lines of development are particularly evident in two highly influential publications, both of which appeared coincidentally in 1972. One was Larry Selinker's paper 'Interlanguage' (Selinker 1972), which can be said to have set in motion, or at least to have given momentum to, the subsequent surge of studies into second language acquisition. SLA took its bearings from formalist 
linguistics and sought to identify how the processes whereby knowledge of the encoded features of a particular second language was acquired. The assumption was that once research had revealed what these processes were, it would provide well-founded criteria for the design of second language teaching.

The second publication of this year was David Wilkins's Linguistic and Situational Content of the Common Core in a Unit/Credit System (Wilkins 1972). This was a Council of Europe pamphlet which was concerned not with the acquisition process but with language learning objectives and how syllabus content might be specified to meet them. Its conclusions were that the emphasis had to be shifted from linguistic form to communicative function, essentially on the grounds that what learners needed to learn was what native speakers actually did with their language in natural contexts of use. Here then the relevant linguistics was that which Firth had defined as the study of 'linguistic events in the social process.' So it would seem that his ideas had not succumbed to the new formalist theory after all as far as applied linguistics was concerned.

Nor indeed as far as disciplinary linguistics was concerned. Two years earlier, William Labov had reasserted a Firthian definition of the discipline in the very title of his The Study of Language in Its Social Context (Labov 1970) and in 1972, in his Sociolinguistic Patterns, we find a statement which echoes Firth's objection to 'structural formalism':

it is difficult to avoid the common-sense conclusion that the object of linguistics must ultimately be the instrument of communication used by the speech community; and if we are not talking about that language, there is something trivial in our proceeding.

(Labov 1972: 187)

Also in 1972, Dell Hymes's article on communicative competence, though written earlier, became widely known and cited as a contribution to Pride and Holmes (1972). Just as Firth had set himself up in opposition to de Saussure, so Labov and Hymes had set themselves up in opposition to Chomsky. But now context linguistics had come out of the cold and had been institutionally reinstated as an alternative orthodoxy. Furthermore, what was so elusive and vague in Firth's theory had become more coherently formulated. Firth described the scope of his linguistics as having to do with

the language of agreement, encouragement, endorsement, of disagreement and condemnation. As language is a way of dealing with people and things, a way of behaving and of making others behave, we could add many types of function - wishing, blessing, cursing, boasting, the language of challenge and appeal, or with intent to cold-shoulder, to belittle, to annoy or hurt, even to a declaration of enmity. The use of words to inhibit hostile action, or to delay or modify it, or conceal one's intention are very interesting and important 'meanings'. Not must we 
forget the language of social flattery and love-making, of praise and blame, of propaganda and persuasion.

(Firth 1957: 31)

Subsequent developments in sociolinguistics and the philosophy of language provided this impressionistic list of functions with the systematic treatment that, as Lyons implies, Firth himself failed to provide. They are reformulated, for example, in Hymes's analysis of the speech event and in Searle's specification of conditions for the performance of speech acts. 'How to do things with words,' as Austin (1962) famously put it - how language functions in communicative use - had become a central consideration, and a context orientation to language study had been given the prominence that Firth had argued for.

What the Council of Europe proposals, and the subsequent development of communicative language teaching were based on, was the restoration of a Firthian functional perspective on the study of language. Extracts from the writings of Hymes and Halliday are cited as the theoretical background in Brumfit and Johnson's book Communicative Language Teaching, published in 1979. Meanwhile, study along the other line of applied linguistics, SLA, following the entirely different theoretical principles of Chomskyan code linguistics, was proceeding apace and getting institutionally established as a disciplinary field of enquiry in its own right.

If applied linguistics is disciplinary, the question obviously arises: which of the two disciplines exemplify the 'sound linguistic principles' which language teachers should follow? As we have seen, the two have historically been at loggerheads. How then can applied linguistics reconcile the disparity between them, bring them cooperatively together in the realisation of what is said to be the other defining feature of applied linguistics: the dealing with real-world problems? In the case of second or foreign language teaching, how can the language subject be so designed that the language is both representative of its communicative use, and at the same time selectively organised so as to correspond or at least be consistent with the natural process of acquisition as revealed by SLA research? It seems obvious that there is a disparity here that needs to be resolved if there is to be any engagement with the real-world pedagogic issues that language teachers are confronted with. And this disparity becomes even more glaring with the proposal that what should be presented to learners should be the 'real' or 'authentic' language that is attested as having been actually produced by its native speakers. Looking back over 50 years, I cannot myself see where the question of how these disparate disciplinary orientations can be reconciled has been seriously addressed - or indeed recognised as worth asking. Instead, they have simply gone their separate ways.

What then does this retrospective view reveal about the role of disciplinarity? What, I think, we need to be clear about is that disciplines of their very nature deal in abstractions, categorising underlying commonalities by disregarding particularities. This necessarily puts them at a remove from experienced reality: 
they can only provide insights by restricting the view. The two disciplinary versions of linguistics are abstractions which offer restricted views of different kinds. What they do is to identify general dimensions of language knowledge and behaviour by disregarding the variables of individual experience. Their validity indeed depends on the elimination of such variables, for the more a discipline seeks to account for actual experience, the less explanatory does it become. The main charge that context linguists level at code linguistics is that its abstractions are remote from how language is actually experienced. But they cannot themselves escape from abstraction or some degree of remoteness from user experience. Firth's objection to Saussure was that he defined language in terms of abstract systems, whereas 'actual people do not talk such a language. However systematically you talk, you do not talk systematics' (Firth 1957: 180). But no linguistics can account for what actual people do. Similarly, Chomsky's formalist linguistics has been attacked on the grounds that it is based on the fictional existence of ideal speaker-listeners and homogenous speech communities. But context linguists also make such a simplifying assumption, for example in their abstraction of common features of linguistic usage in particular communities to identify varieties, or indeed in the specification of speech act conditions and their canonical realisations, which presuppose that these represent the common socio-pragmatic knowledge of a community of language users. Context linguists know full well, of course, that in actual fact such categorical abstractions cannot capture the variable indeterminacy that is a natural and necessary feature of all language use. They are a disciplinary expediency. As Peter Trudgill points out, the dividing up of language use into varieties is

most often linguistically arbitrary, although we do of course find it convenient normally to make such divisions and use names for dialects that we happen to want to talk about for a particular purpose as if they were discrete varieties.

(Trudgill 1999: 122)

But it is not only that such abstract categorisation is convenient. The sociolinguistic study of language cannot exist without it.

So it is that the purpose of linguistics as a discipline, of whatever kind, is to devise conceptual constructs to explain collective communal knowledge and behaviour. In such disciplinary enquiry, individuals only exist as members of categories of different kinds: of a certain social class or ethnic group, as subjects in an experiment, as language learners, as native speakers and so on. The data of actual individual experience are selectively sampled as examples, used to provide evidence of abstract collective categories. Of course, one can argue about the relative relevance and significance of different ways of categorising and the degrees of abstraction they are based on - that one way is essentially trivial, another more valid because it approximates more closely to the reality of language as actually experienced by its users. But it remains an approximation: 
the users are still collectively typified as members of a community. They have to be for the description to lay any claim to be of any significance.

Abstraction, then, is a defining feature of disciplinarity and one can argue about the relative validity of different ways of abstracting in code and context linguistics. But applied linguistics is concerned not with what is valid but with what is useful. Validity has no necessary relevance to utility and utility no necessary reference to validity. Ideas that are theoretically valid may be of little if any practical use. Conversely, ideas that are invalid can be extremely useful, as witness, for example, racial or religious stereotyping or the disregard or denial of global warming. Utility in the shape of sociopolitical or economic expediency is always likely to trump - and I use the word advisedly - the validity of disciplinary findings.

But, as I indicated earlier, it is generally claimed as self-evident that disciplinarity is of its very nature useful, and not only useful but essential as the enabling means whereby problems are resolved, and the more disciplinarity the better. How far is that claim actually borne out in the two developments of pedagogic applied linguistics referred to earlier?

One central disciplinary abstraction that finds its way into the practical pedagogic domain is the concept of competence. This, conceived as what native speakers in a particular community know of their language, is taken over from linguistics and with it the simplifying assumptions that there is a well-defined category of native speakers whose languages and communities are stable and self-enclosed entities. In SLA it is this competence that learners are said to acquire, and their success in doing so is measured by how far they approximate to it along an interlanguage scale. Thus learners are categorised in terms of relative success in acquiring the undefined competence of the fictional category of native speakers - ideal speaker-listeners indeed in homogenous speech communities who know their language perfectly.

Even when the concept is extended from linguistic to communicative competence, the disciplinary abstraction still holds sway. Hymes's familiar formulation is routinely cited as giving the necessary disciplinary authority for the pedagogic practice of communicative language teaching. For Hymes the extent to which one is communicatively competent is how far, given a sample of language, one can judge it to be relatively possible, that is to say in conformity with encoding rules, feasible in the sense of being processible, appropriate to context and attested as having been actually performed. This judgement can, of course, only be made in reference to an established norm, as Hymes makes quite clear:

There is an important sense in which a normal member of a community has knowledge with respect to all these aspects of the communicative systems available to him. He will interpret or assess the conduct of others and himself in ways that reflect a knowledge of each ...

(Hymes 1972: 282) 
So the definition of communicative competence is based on the construct of the distinct community whose normal, that is to say ideal, members have a perfect knowledge of the encoded features of its language and the conventions of its use - for obviously not otherwise would they be able to make judgements as to how far a sample of the language conforms to the communal norm.

And this disciplinary construct of competence, linguistic or communicative, gets carried over into the pedagogic domain. So it is assumed that teaching learners how to communicate in another language is a matter of getting them to replicate the ways normal members of native speaker communities do it. Thus what is possible is defined as what is correct, or accurate, by reference to the ideal encodings represented by the standard language and what is contextually appropriate defined by reference to the conventions of ideal native speaker use. And, over recent years, what is deemed to be appropriate has been conflated with what is actually performed and the language presented to learners should only be what is attested as authentic native speaker usage.

The claim is usually made that it is precisely the focus on communicative function rather than on linguistic form that is so radically innovative about the approach to language teaching ushered in by the Council of Europe in 1972, and which has become the pedagogic orthodoxy ever since. But in fact there is still a focus on form in the Council of Europe specifications and generally in the way the course content of communicative language teaching is usually designed. The difference is that linguistic forms are now paired up with communicative functions as interdependent correlates. Thus learners are taught that, if they want to perform particular communicative acts, there are certain linguistic forms that can be reliably used as suited to the purpose, and that communicating appropriately depends on producing the forms correctly. In short, if you want to be fluent, you have to be accurate. This of course disregards the fact that appropriateness is determined by variable contextual factors and so communicative function is not inscribed in particular encoded forms. To suppose otherwise is to confuse the semantics of the language code with the pragmatics of its use and to misrepresent the very nature of communication. Communicative language teaching defined along these lines is not concerned with the how language actually functions in communication but only with the normative stereotypical form communication would take in a particular community of idealised native speakers.

The projection of this disciplinary abstraction into the practical pedagogic domain persists in the more recent Council of Europe promulgation of the Common European Framework of Reference (CEFR). This, like the Threshold Level some 50 years earlier, is based on the same concept of competence, but this time provides specifications for measuring how far learners have got in acquiring it. Interestingly, here the two lines of development in applied linguistics that are referred to earlier would seem to conceptually converge, in that both are concerned with identifying stages of approximation to native speaker competence. CEFR can be seen as the functional equivalent of the formalist concept of interlanguage. 
What informs both is the assumption that you cannot really be competent unless you conform to norms of how native speakers use the language, and the closer you approximate to these norms the more competent you will be. And, if there is no such conformity, then your linguistic conduct will be interpreted and assessed as inaccurate, inappropriate and evidence that you are an incompetent user of the language.

Competence, whether linguistic or communicative, is then an abstract construct defined in reference to the similar abstract representations of languages and communities as distinct entities. Such abstractions have their validity in the discipline of linguistics, where they are not only, as Trudgill points out, convenient, but are methodologically necessary and sufficient. But how convenient are they for applied linguistics, primarily concerned as it is with usefulness?

The key question here is useful for whom? Whose problems are we seeking to address? The kind of theoretical abstractions that disciplines devise can be very useful in dealing with institutional problems of a sociopolitical kind where it is very convenient to typify individuals and put them into different social or ethnic or religious categories. This makes them easier to manage and control. And of course, if you can claim disciplinary authority for your categorisation, so much the better. In the case of foreign or second language teaching, the construct of native speaker competence solves the problem of what is to be taught, and what therefore is to be tested. This is very convenient for course designers, policymakers and publishers because it gives them something definite to prescribe for teachers to teach, well documented by standard works of reference. It is, of course, especially convenient in the case of English in that sustains the highly profitable ELT industry, the peddling of ELT goods and services which it is assumed that native speakers are uniquely qualified to provide. So this disciplinary construct solves a lot of problems and in this respect one might say that it bears out the applied linguistic claim that disciplinarity provides the means for handling real-world issues. But again we need to ask whose problems and whose reality we are talking about. The competence construct solves the problem of what should be taught. But what of learners? How does it relate to the problems that learners encounter?

In this orthodox conception of the foreign or second language subject, learning is taken to involve conformity. What is learned is given credit only to the extent that it corresponds with what has been taught. If it does not correspond it does not count as learning but is on the contrary seen as a failure to learn. Language assessment is based not on what has been learned but on what has been taught. But, one might reasonably ask, why is it that, in spite of the teachers' best efforts, and all the various methods and approaches that have been proposed over the years, learners still persistently fail to conform? What's their problem? What is their problem? It clearly has not been solved, or indeed even addressed, in the competence-based developments in applied linguistics that I have been discussing. 
The main problem for learners, I suggest, is essentially pedagogically imposed because their learning is actually impeded by the very teaching that is meant to promote it. The language they are confronted with is an abstract construct dissociated from their own experience and this dissociation is emphasised by the customary practice of monolingual teaching. This has the alienating effect of making the foreign language even more foreign. Attempts by learners to reduce its foreignness by relating it to their own language are seen as interference in the approved process of competence acquisition. These so-called errors may be tolerated as interim failures, but ultimately these learning non-conformities need to be corrected if the objective of teaching is to be achieved.

But in producing these non-conformities, widely supposed to be the defective characteristics of learner language, learners are actually doing what all language users do - engaging in code-switching or translanguaging, drawing on and adapting whatever linguistic resources are available to them to get their meaning across. So, as users of their own language, learners quite naturally seek to link the foreign language with the one they are familiar with, by appropriating it as an additional resource in the essentially multilingual process of extending their communicative repertoire. In this way they familiarise the foreign language and make it a reality for themselves. Meanwhile the teacher is striving, in vain, to get them to replicate the ideality of native speaker users, thereby denying this natural learning and using process by getting learners to conform to an artificial construct and so acquire a separate monolingual competence to add to the one they have already got. In enforcing them to conform to how native speakers supposedly communicate so as to replicate their competence the teacher in effect inhibits learners from learning how to use the language as a communicative resource and so develop their general lingual capability. So what we get is glaring disparity between natural multilingual learning and the enforced imposition of monolingual teaching which effectively reduces learners to teachees. No wonder they have a problem.

If applied linguistics is to engage with learners' problems, rather than define them from a teaching point of view by reference to a disciplinary linguistic construct, as having to do with failure to conform to a prescribed competence, we need to consider how a foreign or other or second language looks from the learners' point of view.

And to do this, we have to be wary of convenient categorisation. The research findings of SLA are based on the abstraction of a category of second language learners, so making the simplifying assumption that all learners learn in essentially the same way and that second languages are all alike in being second. But the fact is that, if we consider the real world, we do not and cannot actually know how languages are learned, because all languages and learners are ultimately different and we cannot account for all the variables. A second language is foreign but the nature of its foreignness crucially depends not only on how it relates to a familiar first language but also on how the second language itself 
is perceived. I am not only referring to language distance, the extent to which the code of the two languages are alike, but, more significantly, to how a learner sees the role and status of this second language in relation to their own, what added communicative value it has to offer or how prestigious is the achievement in acquiring it. It is obvious, for example, that German is not foreign for speakers of Polish or Russian in the same way as it is for Dutch or English speakers. Russian is not foreign in the same way as English is in Ukraine, or Turkish is in Greece. So attitudes to the otherness of the foreign language will depend on various factors which have to do, in Bourdieu's terms, with what economic, cultural, social and symbolic capital it is associated with. The symbolic significance of Arabic, for example, makes its foreignness very different for Indonesians than say for Chinese.

In the case of English the dominant factor is likely to be its economic value; the question then arises as to how far this can be dissociated from its cultural and social capital as a native language and from its symbolic capital as the language of neo-colonial oppression and so serve as a relatively neutral means of communication. In other cases, the foreign language may be closely identified with the culture of its primary community of speakers, and this might lend the language a symbolic prestige or, on the contrary, give rise to prejudice against it. Just as individuals variably accommodate to each other so learners variably accommodate to the second language: converging where they can identify with it, diverging where they cannot. And it is this accommodation process that results in the multilingualism of their learning.

So how learners conceive of the foreignness of the L2 has an obvious effect on their motivation. But it also regulates what features of the language they are disposed to acquire. If they seek to appropriate the second language by reference to their own experience of language, as I have argued they do, they will be naturally inclined to focus attention on what is communicatively salient. But many of the formal features they are required to learn have little if any communicative value. They are conventions of ideal native speaker usage which, like received pronunciation, are deemed to represent the norms of what is socially correct linguistic comportment. They are essentially matters of etiquette. Since learners obviously have little or any idea what these norms are, for them, correctness has no obvious purpose, especially if they encounter users of the language who can get by very effectively without it - users they interact with on social media, for example, or celebrities they admire and wish to emulate. These users are likely to be much more real and therefore more influential as role models than an ideal model of correctness which is remote from their experience. It is not surprising that teachers have such a hard time trying to impose it upon them.

How learners process another language, and what aspects of it they process, depend on their conception of its foreignness, which necessarily means that the process will be locally variable and context dependent. This of course is counter to the kind of teacher-imposed competence-based concept of language teaching that I have been discussing, and which has the authoritative endorsement 
of the Council of Europe. Its devising of the CEFR categorises all languages as alike in being foreign and all learners as having the same objective: the acquisition of native speaker competence, represented as well-defined and undifferentiated whatever the language and whatever contexts and purposes learners might need to use it for. Here, for example, is the descriptor for spoken interaction at B2 level:

I can interact with a degree of fluency and spontaneity that makes regular interaction with native speakers quite possible. I can take an active part in discussion in familiar contexts, accounting for and sustaining my views.

Degrees of communicative effectiveness, fluency and spontaneity are here defined uniquely in reference to interactions which native speakers enact in contexts that can be specified as familiar to them. Although the CEFR claims to represent a 'profoundly modified' conception of the aims of foreign language education, its categories of assessment are in line with the traditional objective of foreign language teaching as the acquisition of bilingualism which as Herdina and Jessner observe

has been based on the view of the bilingual as the sum of two monolinguals in one person with two separate language competences. Consequently bilingual proficiency has generally been measured against monolingual proficiency.

(Herdina \& Jessner 2002: 6)

And language competences and proficiencies are defined in reference to abstract native speaker norms. The ideal speaker/listener who knows its language perfectly is still with us.

Because the term 'native speaker' carries undesirable connotations, it has been proposed that it should be replaced by the more politically correct term 'expert user' (e.g. Rampton 1990). But the use of this terminological variant does not alter the learning objective in the CEFR specifications, which remains the acquisition of an ideal competence. There is no recognition that expertise is not an absolute but relative quality, not a matter of how closely learners might approximate to an ideal competence along an assessment scale but how far they can use the resources of the language effectively as appropriate to their communicative purposes. In this sense, learners may be expert users even if their assessed performance falls well short of proficiency as measured by the approved grades. Indeed this would apply to many real, as distinct from ideal, native speakers. The assessment scale in effect sets an objective for acquisition in a foreign language which learners are unlikely to achieve on their own. So the highly convenient usefulness of this particular categorical conception of foreign language for so-called stake holders like policymakers, educational 
administrators and publishers of tests and teaching materials is at the cost of mispresenting the processes of natural language use and learning.

Of course, as I said earlier, we cannot know how individuals experience language as users and learners, and to attempt to describe it in all its variable detail would simply be to accumulate an endless archive of raw data: a collection of samples with no way of determining what they are examples of. We need to make more general inferences by abstracting from the actual at some level. The question is at what level. There has to be some disciplinarity or otherwise applied linguistics has nothing whatever to contribute to the handling of realworld issues.

So I am not arguing against disciplinarity but against the assumption of its primacy as a defining feature of applied linguistics. For this can lead, and has led, to the unilateral imposition of preconceived abstractions which rather than enabling the engagement with problematic issues on the contrary impede it. This is what I referred to many years ago as linguistics applied (Widdowson 1980). But in applied linguistics, I would argue, we need to reverse this dependency relationship and analyse the problem first. Just as I have suggested that learning should determine what is taught rather than the reverse, so I would suggest that the problem should determine what disciplinary constructs and findings are of use. In this way disciplinarity is brought in on site, its role regulated by its practical value. For example, as I have already indicated, dealing with the issue of how learners conceive of the foreignness of the other language might well involve disciplinary insights, not only from linguistics but from social psychology and political history. Similarly, the design of classroom activities might well benefit from the sociology of group dynamics. My argument is not that disciplinarity is in principle irrelevant, but that its relevance has to be demonstrated in practice and on site and not simply taken on trust.

What I am arguing for is applied linguistics as informed local practice based on a critical appraisal of where disciplinary intervention is called for. But I should make it clear that this is not critical applied linguistics in the Pennycook sense, which he views

as a form of anti-disciplinary knowledge, as a way of thinking and doing that is always questioning, always seeking new schemas of politization.

(Pennycook 2001: 173)

The problem I have with this view is that redefining applied linguistics as a new form of knowledge is not to deny its disciplinarity but to confirm it as its primary feature. For what counts as disciplinary knowledge is not fixed but has always been subject to various ways of thinking and doing and questioning, coming up with schemas of different kinds. So Pennycook is in fact proposing not an anti-disciplinary but alternative and politicised pro-disciplinary way of conceiving of applied linguistics. Potentially significant though such a reconceptualisation might be, the question remains as to how it can be usefully 
implemented for the solving of actual problems in the practical domain. You can go on thinking, questioning and seeking on a disciplinary level without ever engaging with problematic issues that real people actually experience.

Indeed that is what applied linguistics has tended to do, and it has become institutionally established not as an effective means for addressing real-world issues but as a field of academic enquiry, not essentially different from any other, with its own university departments, its own associations and, of course, its own peer-reviewed learned journals. The peers who do the reviewing are typically themselves academics who will evaluate the learnedness of contributions by reference to disciplinary criteria. These contributions subsequently acquire relative significance by reference to what other academics have written and assigned an impact value by bibliometrical quantification, and the journal is ranked on the academic league table accordingly. What impact the contributions have on the extra-mural world outside academia is not measured, and indeed does not seem to be considered of any relevance. It may be claimed that they nevertheless show that applied linguistics is in a state of preparedness for the principled handling of a range of distinct types of 'real-world issues,' but, in the absence of evidence, one just has to take this on trust. On the face of it, what we seem to have is a disparity between what is promised in principle and what is actually delivered in practice.

Let me stress again that I am not arguing against disciplinarity, but that it can only be a defining feature of applied linguistics if it can be brought to bear on issues in the real world, its abstractions being actualised on site as and when required. So we first need to consider the nature of the problem to be handled as a crucial precondition on deciding what kind of disciplinary intervention is appropriate and relevant to the local context of situation.

And here we return to J.R. Firth. For the notion of 'context of situation' was central to his proposal for a linguistics of language use. This is how he describes it:

My view was, and still is, that 'context of situation' is best used as a suitable schematic construct to apply to language events, and that it is a group of related categories at a different level from grammatical categories but rather of the same abstract nature. A context of situation for linguistic work brings into relation the following categories:

A. The relevant features of participants: persons, personalities.

B. The verbal action of the participants.

i. The non-verbal action of the participants.

ii. The relevant objects.

C. The effect of the verbal action.

(Firth 1957: 182)

As noted earlier, Firth never managed to develop this schematic construct into a systematic and coherent theory, and so it was found wanting in validity from a disciplinary linguistics perspective. But, from the perspective of applied 
linguistics, it provides an excellent framework for the analysis of the problems that it claims to deal with. Firth took the concept over from Malinowski, who used it to give an ethnographic account of the particular language behaviour of the Trobriand Islanders, and it was Firth's attempted systematisation of this descriptive schema into a general theory of meaning that proved so elusive. But we can, so to speak, relocalise Firth's schema in Malinowski fashion by using it describe the local contexts in which language-related problems are situated.

Relevance is the key concept. Contextual relevance can only be relative, locally identified and not determined in advance. So in the case of second language pedagogy that I have been considering, what, we might ask, in a particular context of situation, is the relevant way of conceiving of the object language and the objective of learning, what kind of verbal and non-verbal action is it relevant for the classroom participants to engage in, and what effect does it have? But the Firthian schema is, I would argue, not only applicable to the applied linguistics of foreign or second language teaching but provides the analytic framework for the principled handling of a range of distinct types of 'realworld' issues. What is relevant, for example, about the sociocultural or political preconceptions and misconceptions of participants in contexts of situation like negotiations aimed at conflict resolution, or like the interrogation of refugees? What is relevant about their verbal and non-verbal actions and their effects effects that may well quite literally be matters of life and death. I would argue that it is only after analysing the situated 'real-world' issues, and identifying what is locally relevant, does it make sense to decide what kind of disciplinary intervention is relevant for handling them.

Back then to Firth and to 1957. It is true, of course, that we have come a long way since then - through 38 volumes of the journal Applied Linguistics and 50 years of BAAL - a history of very considerable intellectual achievement - a cause for celebration on this occasion which I would not want to question. But history is always a matter of variable, ultimately subjective interpretation, and the historical account I have given here is of course no exception. And, being myself a participant in this history, my account is bound to be particularly partial. But my enumerating of an old theme may perhaps have some validity - or usefulness - in provoking a critical consideration of the nature of the activity that this association was founded to promote 50 years ago.

\section{References}

Austin, J.L. 1962 How to do things with words. Oxford: Oxford University Press Brumfit, C.J. and Johnson, K. 1979 The communicative approach to language teaching. Oxford: Oxford University Press.

Bygate, M. and Kramsch, C. 2000 Editorial. Applied Linguistics, 21(1): 2.

Chomsky, N. 1957 Syntactic structures. The Hague: Mouton.

Firth, J.R. 1957 Papers in linguistics (1934-51). Oxford: Oxford University Press. 
Halliday, M.A.K., McIntosh, A. and Strevens, P. 1964 The linguistic sciences and language teaching. London: Longman

Herdina, P. and Jessner, U. 2002 A dynamic model of multilingualism. Bristol: Multilingual Matters.

Hymes, D. 1972 On communicative competence. In Pride, J. and Holmes, J. (eds), Sociolinguistics: Selected readings. Harmondsworth: Penguin Books.

Labov, W. 1970 The study of language in its social context. Studium Generale, 23: $30-87$.

Labov, W. 1972 Sociolinguistic patterns. Oxford: Blackwell.

Lyons, J. 1966 Firth's theory of 'meaning' In Bazell, C.E., Catford, J.C., Halliday, M.A.K. and Robins, R.H. (eds), In memory of J.R. Firth. London: Longman.

Palmer, F.R. (ed.) 1968 Selected papers of J. R. Firth 1952-1959. London: Longman.

Pennycook, A. 2001 Critical applied linguistics: A critical introduction. Mahwah, NJ: Lawrence Erlbaum.

Rampton, B. 1990 Displacing the 'native speaker': Expertise, affiliation, and inheritance. ELT Journal, 44(2): 97-101.

Searle, J.R. 1969 Speech acts. Cambridge: Cambridge University Press.

Selinker, L. 1972 Interlanguage. International Review of Applied Linguistics, 10(3): 209-231.

Simpson, J. (ed.) 2011 The Routledge handbook of applied linguistics. Abingdon, Oxon and New York: Routledge.

Trudgill, P. 1999 Standard English: What it isn't. In Bex, T. and Watts, R.J. (eds), Standard English: The widening debate. Abingdon, Oxon and New York: Routledge.

Wilkins, D. 1972 The linguistic and situational content of the Common Core in a unit/credit system. Strasbourg: Council of Europe.

Widdowson, H.G. 1980 Models and fictions. Applied Linguistics, 1(2): 165-170.

Widdowson, H.G. 2000 On the limitations of linguistics applied. Applied Linguistics, 21(1): 3-25.

Widdowson, H.G. 2005 Applied linguistics, interdisciplinarity, and disparate realities. In Bruthiaux, P., Atkinson, D., Eggington, W., Grabe, W. and Ramanathan, V. (eds), Directions in applied linguistics. Essays in honor of Robert B. Kaplan. Bristol: Multilingual Matters. 